\title{
Documentación
}

1. Análisis del Banco Mundial sobre la economía salvadoreña.

1.1. El grupo del Banco Mundial en El Salvador.

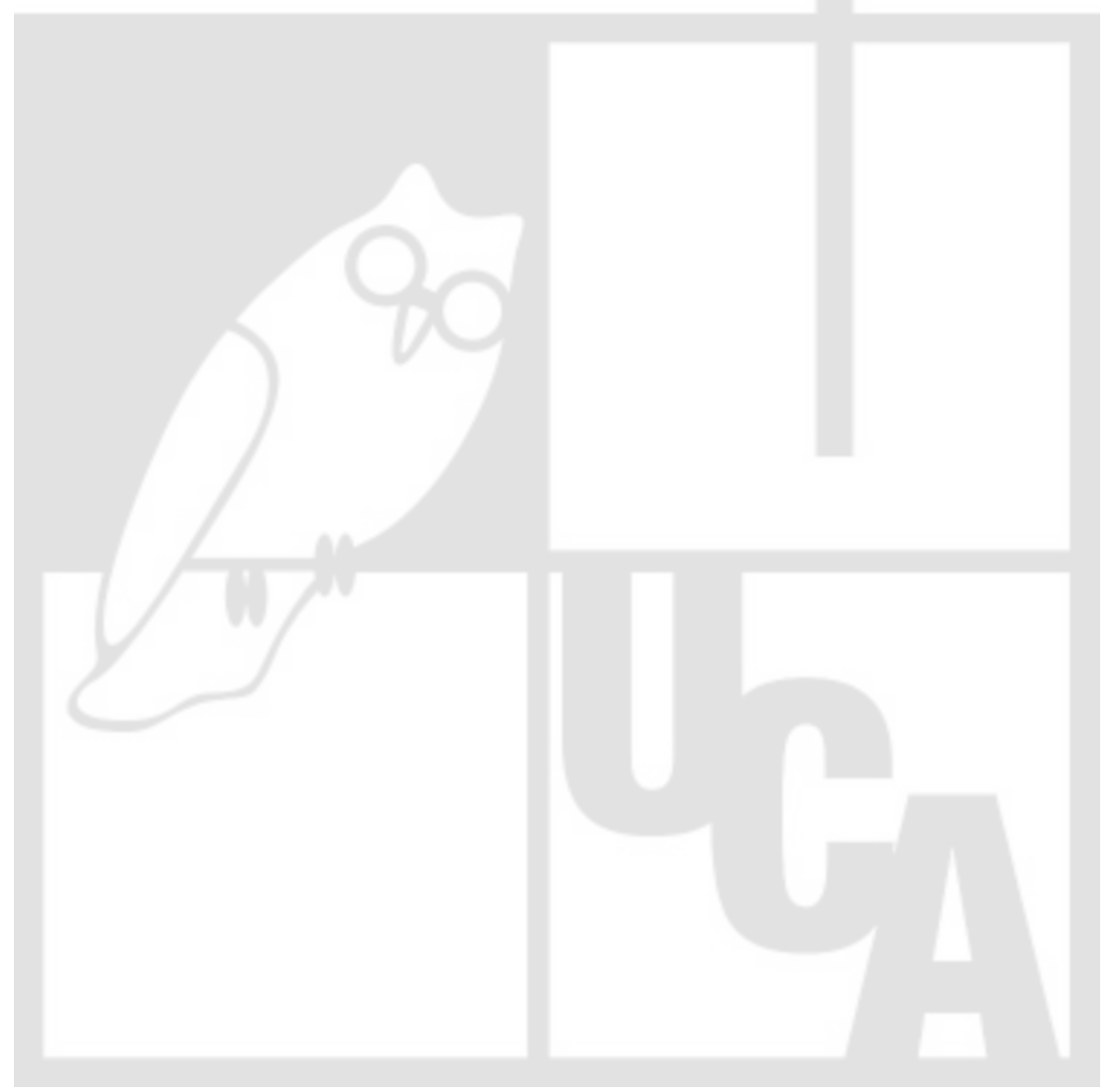




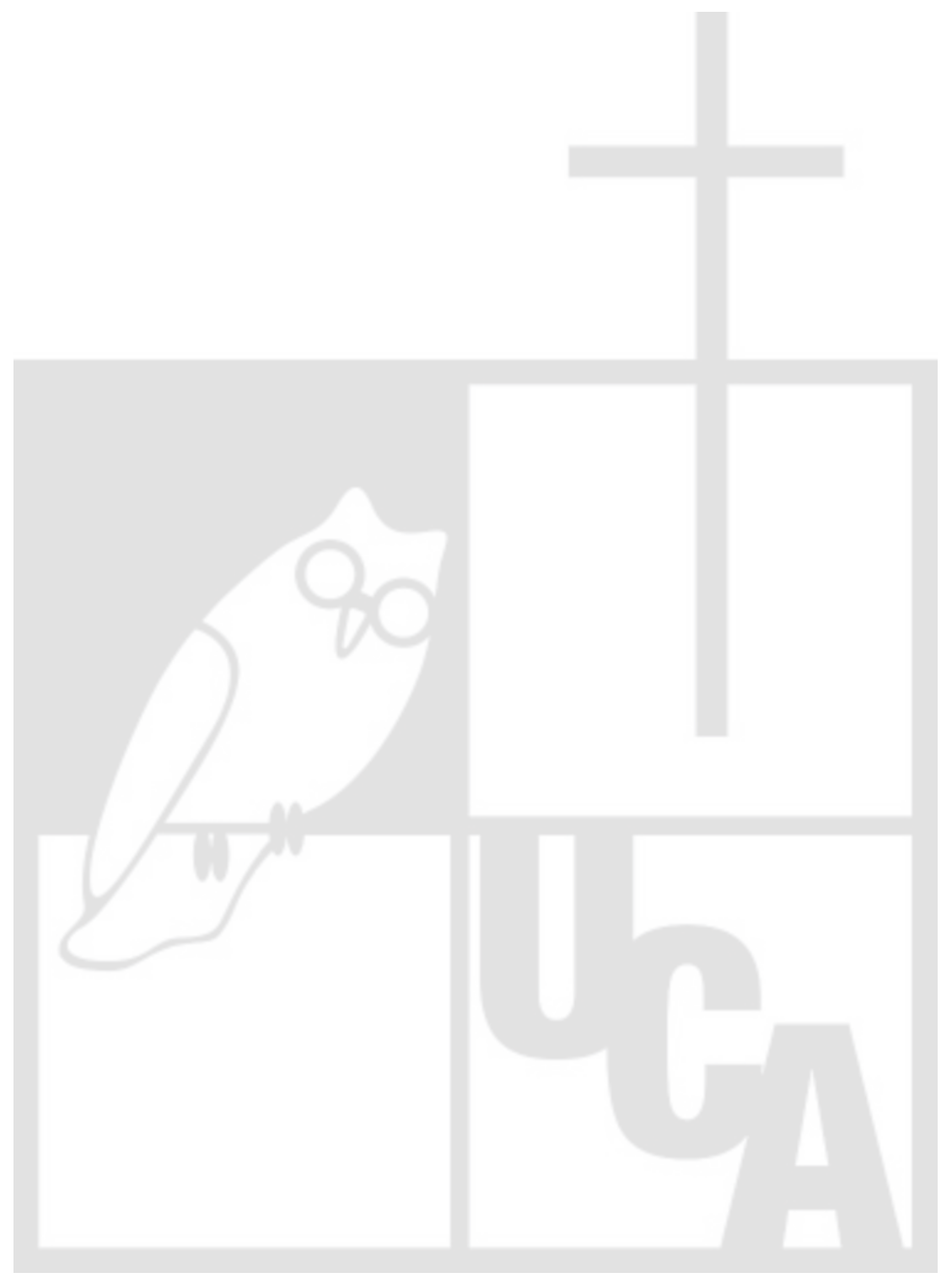

Digitalizado por Biblioteca "P. Florentino Idoate, S.J." Universidad Centroamericana José Simeón Cañas 


\section{Análisis del Banco Mundial sobre la economía salvadoreña. 1.1. El grupo del Banco Mundial en El Salvador.}

El Salvador es el país más pequeño de América Central y, con sus 5.8 millones de habitantes en una superficie de $21,000 \mathrm{~km} 2$, uno de los países con mayor densidad de población del hemisferio occidental. Su base de recursos naturales es limitada y no le queda frontera agrícola. Alrededor del 60 por ciento de la población vive en zonas rurales y más del 80 por ciento de los productores agrícolas trabajan en explotaciones de superficie inferior a 3 hectáreas. Sus indicadores sociales se encuentran entre los peores de América Latina y sus ingresos per cápita fueron de 1,810 dólares en 1997. por lo que figura también entre los países más pobres de la región.

El país se ha esforzado por pasar de una sociedad castigada por la guerra y sumamente fragmentada a una sociedad basada en una mayor participación económica y social, con una economía de mercado. Además del establccimiento de un entorno macroeconómico estable, el Gobierno se ha propuesto abordar cuatro grandes desafíos: (i) modernización del sector público; (ii) creación de condiciones favorables al sector privado y al crecimiento orientado por las exportaciones; (iii) reducción de la pobreza e inversión en capital humano, y (iv) fortalecimiento de la gestión del medio ambiente y de los recursos naturales.

Desde 1992, el Banco apoya los esfuerzos estratégicos del Gobierno de El Salvador para consolidar la paz y colocar al país en el camino hacia el desarrollo sostenible. Esta estrategia requiere no sólo de un fuerte crecimiento económico, sino también medidas enérgicas para reducir la pobreza y mejorar el nivel de vida de la mayoría de los salvadoreños. Actualmente hay siete préstamos en ejecución, y el Directorio Ejecutivo acaba de aprobar otro, que está a la espera de ser implementado, por un valor de 298 millones de dólares.

\section{Del conflicto a la pobreza}

El 16 de enero de 1992, el Gobierno de El Salvador y el Frente Farabundo Martí para la Liberación Nacional (FMLN) firmaron un Acuerdo de Paz que puso fin a un conflicto de 12 años de duración. En la guerra civil de El Salvador no hubo ningún ganador, pero sí muchos perdedores. El conflicto costó unas 75,000 vidas y dejó a miles de personas desplazadas, huérfanas o discapacitadas y provocó una migración masiva de resultas de la cual aproximadamente uno de cada cinco salvadoreños vive fuera del país. La guerra provocó también cuantiosas pérdidas materiales; se calcula que los daños causados por la guerra se elevaron a unos 1,500 millones de dólares, sólo en infraestructura. Más difíciles de medir fueron la disgregación del tejido social del país, la polarización política y el debilitamiento del aparato institucional. Una de las principales secuelas de la guerra ha sido el espectacular aumento de los delitos con violencia, que el Gobierno está intentando combatir.

Durante los últimos cinco años, el Gobierno y el pueblo de El Salvador se han esforzado por reconstruir la estructura económica, social, política e institucional del país. El hecho de que no hubiera ganadores en el conflicto ha hecho más fácil forjar un consenso acerca de las oportunidades de desarrollo del país. Aunque se han hecho progresos considerables, aún queda mucho por hacer. Se requiere un crecimiento más rápido para consolidar la paz y aliviar la pobreza.

En este momento decisivo, El Salvador ha decidido dar un gran salto adelante para ponerse a la altura de las economías de alto rendimiento. El propósito es conseguir un crecimiento rápido y equitativo aumentando la competitividad a escala mundial e iniciando una nueva fase de desarrollo. El Salvador está llevando a cabo au- 
daces reformas económicas para convertirse en una economía más abierta, con un sector privado dinámico, orientado a las exportaciones y sintonizado con los mercados internacionales, y un sector estatal reducido y sólido que facilite las actividades del sector privado.

\section{El Salvador y el Grupo del Banco Mundial}

El Banco Mundial está ayudando a El Salvador en su proceso de reforma de varias maneras:

\section{Alivio de la pobreza en El Salvador}

Imensificación de la competencia: el camino hacia la globalización. Aunque la recuperación económica ha sido impresionante, el Producto Interno Bruto per cápita sigue siendo inlerior al nivel anterior a la guerra, la expansión económica ha estado dirigida por los sectores no comerciables, y las exportaciones de mercancías, aunque en crecimiento, son todavía considerablemente más bajas que a principios de los años setenta. Hace falta un crecimiento rápido soslenido, pero también de amplia base, para reducir la pobreza. La estrategia del Gobierno consiste en hacer que la base competitiva de El Salvador sea no su mano de obra barata sino una productividad elevada, es decir, en lograr una ventaja competitiva. más que comparativa.

El Programa de Competitividad. respaldado por el actual provecto de asistencia técnica para la mejora de la competitividad, del Banco Mundial, por un valor de 16 millones de dólares, consta de tres elementos principales: (i) mejora de las condiciones para la actividad cconómica adoptando una nueva ley de inversiones, medidas lcgislativas para la protección del consumidor, prestación de servicios de infraestructura por el sector privado, prolundización de los mercados financieros y Je capiales, eliminación de las barreras al comercio que aún persisten, adopción de un crilerio de agrupación de sectores clave y reforma de los registros jurídicos; (ii) mejora de la absorción de tecnología mediante el aumento de la calidad y el fortalecimiento de las políticas de capacitación técnica, y (iii) logro de un consenso nacional sobre los planes de competitividad por conducto de un programa de información pública y viajes de estudios para evaluar la experiencia internacional.

Mercados fincancieros y de capitales. Una cuestión prioritaria para el Gobierno es velar porque el sector financiero lavorezca un crecimiento basado en la productividad. El asesoramiento y la asistencia técnica al sector financiero es uno de los principales elementos de apoyo del Grupo del Banco al programa olicial de aumento de la competitividad.

El Gobierno ha definido el acceso a la información y a los conocimientos como elemento clave para su estrategia de competitividad y desarrollo social, y ha solicitado apoyo al Banco para fomentar en la sociedad una aclitud de aprendizaje. Preocupa que partes de la socie- dad queden atrás en el camino hacia la globalización. A menos que se vea complementada por políticas sociales firmes, la estrategia puede llevar a una mayor desigualdad y a la marginación de las comunidades pobres, especialmente en las zonas rurales. El Gobierno y el Banco han examinado los medios para conseguir una integración más plena del programa social y el de competitividad.

Pobreza rural. El crecimiento y la productividad de la agricultura siguen siendo prioritarios para El Salvador, pero para avanzar en forma sostenida hacia la reducción de la pobreza habrá que aumentar también el acceso de los pobres a actividades rurales no agrícolas que generen ingresos mayores y más estables. El Banco está apoyando esta estrategia nacional mediante un proyecto de inversiones y reforma del sector agrícola por valor de 40 millones de dólares, con el que se está financiando asistencia técnica, equipo, capacitación, obras públicas y costos incrementales de operación para apoyar la reforma y el desarrollo institucional del Ministerio de Agricultura y Ganadería y el Centro Nacional de Tecnología Agropecuaria (CENTA). El proyecto también está contribuyendo a generar tecnología agraria inás productiva y ecológicamente sostenible mediante investigaciones y servicios de extensión agraria dirigidos a pequeños y medianos agricultores, incluidas las mujeres.

\section{Aspecto social de la reducción de la pobreza}

El Gobierno no sólo ha mantenido un firme compromiso hacia el alivio de la pobreza sino que también está lormulando de nuevo su estrategia, adoptando un enfoque amplio de la reducción de la pobreza y el desarrollo social y buscando una complementariedad plena entre sus planes económicos y sociales. Hasta la fecha, la estrategia social del Gobierno ha tenido tres vertientes, de acuerdo con las recomendaciones del Banco: alto crecimiento económico, mejora del acceso a los servicios sociales, especialmente la educación básica, y una sólida red de protección social.

Capital humano: educación y salud. La mejora del capital humano exige aumentar el gasto público en los sectores sociales y mejorar la eficiencia de la prestación de servicios. El gasto en educación y salud ha aumentado en los últimos años, desde el 1.8 y 0.9 por ciento del Producto Interno Bruto, respeclivamente, en 1991, hasta el 2.2 y 1.4 por ciento en 1995, pero aún representa una inversión considerablemente deficiente en capital humano. El Gobierno se propone aumentar la proporción del sector social desde el $\mathbf{3 0 . 2}$ por ciento de los gastos presupuestados en 1995 hasta el 50 por ciento en 1999.

A medida que avanzan las reformas, cada vez es más necesario tener en cuenta también las limitaciones en el nivel secundario. Los índices más altos de malriculación y terminación de los estudios, junto con una creciente demanda de mano de obra calificada, pronto 
comenzarán a ejercer presión en el nivel secundario, donde la cobertura y la calidad dejan que desear. Sólo una cuarta parte de los jóvenes de 15 a 19 años de edad están matriculados en escuelas secundarias, lo que representa menos de la mitad de la tasa de matrícula correspondiente a la región. Cerca de dos terceras partes de la fuerza de trabajo carece de calificación y la media de años de instrucción es de 4.4; alrededor de la cuarta parte carece de educación escolar, y sólo el 12 por ciento tiene más de diez años de escolaridad. En las zonas rurales sólo se encuentran el 6 por ciento de las escuelas secundarias.

El proyecto de modernización de la educación básica, por un total de 34 millones de dólares, está mejorando la calidad de la enseñanza elemental, favoreciendo el acceso de los niños pobres al sistema educativo y promoviendo la igualdad entre los sexos en la enseñanza, por conducto del hoy renombrado programa de educación EDUCO, de base comunitaria.

El proyecto de educación secundaria, por un total de 58 millones de dólares, tiene por objeto facilitar a los nuevos trabajadores que se incorporan a la fuerza de trabajo del país un mayor acceso a la enseñanza secundaria y, más adelante, promover la competitividad del país en el extranjero. Ello supondrá el aumento de la cobertura en las zonas rurales, una mayor eficacia en función de los costos, más intervención del sector privado, mejora del contenido y la pertinencia de los planes de estudios y mayor atención a las necesidades de las mujeres que estudian.

Mejor gestión del medio ambiente: sostenibilidad del crecimiento económico

El Salvador padece una grave degradación del medio ambiente. A causa de la presión demográfica y de la penetración de la agricultura en las zonas forestales y marginales, sólo se conserva el 2 por ciento de la cubicrta forestal primaria y sólo el 12 por ciento del territorio tiene cubierta forestal de algún tipo. La topografía del país es muy accidentada y cerca del 65 por ciento de las tierras no son cultivables, por tener pendientes de más del 12 por ciento. La destrucción de los bosques ha contribuido a la erosión del suelo, lo que ha afectado al crecimiento de la productividad y ha limitado la capacidad de los acuíferos para retener el agua de lluvia. El problema de la degradación de los recursos naturales está inextricablemente vinculado a la pobreza rural.

Además, la rápida urbanización ha sobrepasado la capacidad del sector público para of recer infraestructura y scrvicios. Cerca de la mitad de los residuos sólidos en las ciudades quedan sin recoger, mientras que las localidades rurales carecen de capacidad para la eliminación de desechos.

La función del Banco en cuestiones institucionales y de política en relación con el medio ambiente se centra en tres esferas: concesión de títulos de propiedad sobre la tierra, logro de un consenso sobre el medio ambiente y ordenación de los recursos naturales en las explotaciones agrícolas. El actual proyecto de administración de tierras del Banco, por un total de 50 millones de dólares, apoya la regularización del registro de propiedades en los aproximadamente 1,6 millones de parcelas urbanas y rurales, así como el establecimiento de un registro nacional de tierras independiente y un sistema catastral. Una mayor seguridad en la tenencia de tierras permitirá ampliar el horizonte de planificación de los agricultores y facilitar el acceso al crédito, con lo que aumentarán los incentivos para las inversiones en conservación del suelo y diversificación de ingresos.

El Banco contribuye también a los programas ambientales del Banco Interamericano de Desarrollo y de la USAID, ayudando a conseguir en el país una mayor sensibilización y consenso acerca de cuestiones ambientales de alcance general.

Además, el proyecto de desarrollo rural y gestión de los recursos naturales, propuesto por el Banco, examinará la prestación de apoyo para mejorar las prácticas de gestión de los recursos naturales, trabajando en las localidades y las explotaciones agrícolas.

Modernización del sector público: mejora de la prestación de servicios en una economía competitiva

El gobierno es consciente de que la actual estructura del sector público y su incapacidad para prestar servicios adecuados y eficientes serían un obstáculo en sus esfuerzos de aplicación de los programas sociales y de competitividad. A pesar del considerable avance político y económico de los últimos años, el sector público de El Salvador aún adolece de importantes deficiencias: $(i)$ un Estado hipertrofiado y centralizado; (ii) baja eficiencia causada por su estructura de organización, una débil gestión financiera de los recursos humanos y la baja profesionalidad de la administración pública; (iii) una prestación de servicios inadecuada, e (iv) insuficiencia de la infraestructura y equipo administrativos.

Con arreglo al Programa de modernización del sector público, el Estado se retirará de aquellas actividades de las que puede ocuparse mejor el sector privado. El propósito es conseguir un Estado más reducido pero más fuerte, que se dedique ante todo a aplicar las políticas sociales y favorecer el desarrollo impulsado por el sector privado.

En 1996, el Banco Mundial aprobó un proyecto de asistencia técnica para la modernización del sector público, por un total de 24 millones de dólares, para ayudar al Gobierno a definir las nuevas funciones del sector público y sus entidades más importantes, reforzar las operaciones de las entidades que permanezcan en el sector público y hacer que el sector privado preste servicios públicos. El proyecto está prestando asistencia técnica 
para la reestructuración institucional del sector público, el fortalecimiento de la capacidad de gestión institucional y el establecimiento del marco jurídico e institucional para el proceso de privatización.

Mediante el provecto de asistencia técnica al sector de la ene'rgía, por un total de 11 millones de dólares, el Banco está ayudando a El Salvador a mejorar el marco jurídico, institucional y normativo de su sector energético, a promover políticas acertadas de planificación y fijación de capacidad de gestión del organismo regulador, la Comisión Ejeculiva Hidroeléctrica del Río Lempa (CEL).

Además, con el proyecto de modemización del sec1or de la chergía, por un total de 65 millones de dólares, e) Banco está sulragando estudios y prestando asistencia lécnica. y apoyando la rehabilitación de las centrales eléctricas de Guajoyo, Cerrón Grande y 5 de Noviemhre. la adición de una tercera unidad en Cerrón Grande y la modernización de sistemas de telecomunicaciones e intormación de CEL.

\section{Ia Corporación Financiera Internacional en El Sal- vador}

La Corporación Financiera Internacional (CFI), micmbro del Grupo del Banco Mundial, es la mayor fucnte multilateral de financiación de inversiones en capilal social y préstamos para proyectos del sector privado en países en desarrollo. La CFI, que tiene experiencia en todo el mundo en la privatización de entidades públicas. contribuye en forma decisiva a dar seguridad a los polenciales inversores privados y al mismo tiempo protege los intereses del país receptor. En El Salvador, la CFI ha efectuado tres inversiones.

Cemento de El Salvador S.A. (CESSA). Este préstamo de la CFI por un total de 22 millones de dólares está ayudando a CESSA en su proyecto de expansión y modernización, que aumentará la capacidad global en un 55 por ciento. El proyecto tiene dos componentes: (i) una nueva línea de producción de cemento en sus instalaciones primarias del Departamento de Melapán y (ii) mejora de las instalaciones con que cuenta la empresa. En este último elemento se incluyen medidas de protección ambiental y el cierre de dos líneas de producción de cemento que tienen una tecnología menos eficiente.

Implementos Agricolas Centroamericanos S.A. de C.V. (IMACASA). Este préstamo de 2 millones de dólares de IMACASA, uno de los mayores fabricantes de aperos de América Central, sufragará el programa de inversiones de la empresa, que tiene por objeto mejorar su posición compelitiva modernizando y ampliando las instalaciones de fabricación, aumentar el capital de operaciones y diversificar su base de ventas buscando alianzas internacionales y nuevos mercados.

Telemóvil E/ Salvador, S.A. Este proyecto consta de dos inversiones: una, por valor de 1.7 millones de dólares, apoya la construcción y explotación de un sistema de telefonía celular en las principales ciudades de El Salvador; otra, de 8,0 millones de dólares, se propone ampliar la capacidad de la red de telefonía celular en el país.

Junio de 1998. 